\title{
Changing of the Guard for Anatomy
}

\author{
Salih Murat Akkın \\ Department of Anatomy, Faculty of Medicine, Cerrahpaşa Medical Faculty, Istanbul University, Istanbul \& \\ Medical School, SANKO University, Gaziantep, Turkey \\ Anatomy 2014;8:1, (C) 2014 TSACA
}

Seven years have passed since the launch of our journal Anatomy (International fournal of Experimental and Clinical Anatomy) in 2007. This was the crawling period of our baby journal. The first issue contained only the abstracts for the XI National Congress of Anatomy with International Participation. We, as the founding Editorial staff, started with a large Scientific Advisory Board with international participation of a great number of prominent anatomists. Over 200 manuscripts were submitted to Anatomy between 2007 and 2014. As an annual journal, we published seven regular issues containing a total of 74 papers. I extend my special thanks to all authors for providing us with the opportunity to review their work for publication. I also express my appreciation to all reviewers who evaluated the submitted manuscripts. Finally, I would like to thank each member of the Editorial Team for its effort to improve our journal in this period.

With this editorial, I would like to announce the change of the Editorial staff and the start of a new era of our journal. Prof. Gülgün Şengül from Ege University, İzmir, who served as Associate Editor of the journal, has assumed full editorial responsibility as the new Editorin-Chief of Anatomy by this issue. This is a real changing of the guard for our journal because the Editorial Team and Scientific Advisory Board as a whole, moreover, will become rich with the joining of new international colleagues starting from next issue. Together with this internationalization, I am sure that our journal Anatomy will display an increasing performance level in the way of scientific quality and impact under Gülgün's competent leadership in the near future.
Correspondence to: Salih Murat Akkın, MD

Department of Anatomy, Cerrahpaşa Medical Faculty,

Istanbul University, Istanbul, Turkey

Phone: +90 2124143057

e-mail: salihmuratakkin@gmail.com

Conflict of interest statement: No conflicts declared. 